\title{
Helping Adult and Young Learners to Communicate in Speaking Classes with Confidence
}

\author{
Ali Derakhshan \\ Assistant Professor at Golestan University, Department of English Language and Literature, Gorgan, Iran \\ a.derakhshan@gu.ac.ir \\ Farahnaz Tahery \\ Nasrin Mirarab

\begin{abstract}
Department of English Language Teaching, Gorgan Branch, Islamic Azad University, Gorgan, Iran Department of English Language Teaching, Golestan Science and Research Branch, Islamic Azad University, Gorgan, Iran Nazift134756@yahoo.com,n.mirarab90@gmail.com
\end{abstract}

\section{Doi:10.5901/mjss.2015.v6n2p520}

\begin{abstract}
It has been more than four decades that participating in English conversation classes and motivation theories in learning a foreign language have been considered as an important issue in language learning. It is believed that English oral communication is necessary in the professional world (Pattanapichet \& Chinaokul, 2011). As learning a new language is a challenging issue for most learners English as foreign language (EFL), and also for learners of English as second language (ESL), the confidence plays the key role in learning through which students can improve one of important skills in language learning "speaking", while this is what was ignored in traditional methods. The aim of this review is to represent the implementation of various experiences which would be highly useful for teachers in the process of teaching EFL/ESL. As a result of the significant difference between young and adult learners, teachers' awareness can vigorously help them in their career. It is strongly posited that students' motivation along with a good relationship between students-teacher and students themselves in class can actively support the amount of success for students by taking part in speaking tasks. Moreover, the tools and methods which a teacher chooses to foster students' oral activities are considerable to great extent.
\end{abstract}

Keywords: Speaking opportunities; Confidence; Motivation in oral activities; EFL learners

\section{Introduction}

Teachers improve one of the important skills in language learning namely 'speaking', which has been undervalued in conventional methods. Young and adult learners are different in learning a new language. So, teachers' awareness may be useful in teaching. Learners' motivation is considered as a powerful tool in classroom. Furthermore, good relation between learner-teacher and learners-learners encourages learners to speak more successfully in the classroom and in society. The methods and the tools selected by the teacher to foster learners' oral activities are also considerable. Motivating learners as mentioned above is a very important task. Increasing the number of learners who are able to communicate with new language in a class after a period of time indicates the teacher's success and ability.

One of the devices in learning a foreign language is practicing and using it in different situations. Being confident in speaking is largely important to ESL learners. Confident students speak more and participate in communications. The role of the teacher is very important in encouraging ESL learners to take part in communications and speak with less stress (Toste, 2011). Moreover, making ESL learners speak in class is one of the important problems teachers face; however, it is necessary to overcome and encourage learners to use their speaking skills. Learners are afraid of simple slip of the tongue and seeing others to laugh. Language learners prefer writing to speaking. They are more skilled in writing.

It is common that young students learn faster and easier than adult learners in foreign language classes (Staib, 2008). Most adults are excited in learning a new language and improving language abilities, but keeping them motivated to learn throughout the course may be difficult. Adults are different from the young students in motivation in oral activities (Tutaj, 2011). Drama or video theaters are effective ways to help young learners to motivate them in speaking tasks (Brouilitte, 2012). This paper provides some suggestions to improve both adult and younger learners' speaking. It also provides some practical ways for teachers to motivate their students. 


\section{Literature Review}

\subsection{Goals of Speaking}

Speaking does not mean only knowing the linguistic parts of a message; developing oral activities needs more than vocabulary memorization and grammatical comprehension. One problem of everyday classes and oral tasks' goals is the inconsistency between class and course goals meaning that, in daily activities, some teachers do not provide opportunities for real practice in speaking. In addition, the teachers must consider meeting learners' interest and needs. Learners should participate in classroom's oral tasks. The learners should convert their thought in second language speaking (Chastain, 1988).

\subsection{Motivation in Oral Activities}

Cutron (2009) believes that: "we can assume that language anxiety has a debilitating effect on learners' success in L2, and that teacher should make an effort to alleviate it in their classroom" (p.59). The teacher requires motivating the learners in order to reduce the learners' anxiety, however, when learners have the opportunity to talk about the topic they like, they will be more interested in learning new language using it instead of native language. In contrast, some learners are under peer pressure, so they are afraid of being mocked by classmates whenever they stumble or make mistakes.

The teachers are required to motivate ESL learners to improve speaking skill in achieving the goals. The supporting classroom atmosphere and linguistics supporting are the two ways which may help learners learn English better. Learners can support each other by working as a team and also the sentences teachers repeat throughout the class: "sorry being late, repeat the lesson, please, etc.) could be a habit (Skeffingtone, 2011). Learners are low motivated because the teachers always let learners read and discuss some dialogues and topics in the textbooks, but the teacher do not give them any related information for real-life; in addition, teachers take more control on English speaking class and do not give learners chance to freely express themselves (Martin, 2003).

When teachers employ essential words or phrases, the learners would be encouraged to make use of those words in daily life. It turns out to become a habit and gradually increase the vocabularies and expressions which are more interesting (Pesce, 2013). When teachers teach new words in context, they will be more sensible and easier to understand than isolated words. When they give a familiar context, learners can discuss it and talk about their points of views. Also, when they are presenting something, teachers should praise their strong pints and make as few as corrections. Reminding just some important mistakes is better than interrupting them which lead to lack of confidence (Pesce, 2013). These activities will persuade learners to improve their knowledge of vocabulary and be motivated to speak more.

Thanasoulas (2002) indicates preconditions to give effective motivation including teacher proper behavior, attractive classroom atmosphere, and appropriate group in cohesive learner group. To establish an acceptable relationship between teacher and learners, teacher's behavior plays a crucial role as a motivation tool.

Moreover, good atmosphere in the class improves learning because learners can express their ideas without ridiculing. Anxious learners are unlikely to improve their motivation to speak and learn, but in safe classroom condition they have opportunities to learn and support their learning effort. Learners are interested to learn innately, and teachers can help them to increase their goal-orientedness by allowing learners to explain their own personal criteria about their goals. Learners need to be aware of the second language learning nature to be master in L2 by using optimal methods.

Furthermore, to avoid distracters and demotivation in learners' skills, there are two strategies which help them a) increasing learners' self-confidence, and b) creating learner autonomy. In order to increase learners' motivation, teachers can provide regular experiences of success, make their contribution interesting, and use encouraging words to make a less stressful context.

\subsection{History of Teaching Speaking}

Traditional teaching foreign language theory puts emphasis on teachers' explanation of vocabulary, grammar and other points which are in text. Learners were unable to grasp new language quickly. Kayi (2006) indicates that "for many years, teaching speaking has been ...valued and English language teachers have been continuing to teach speaking just as a repetition of drills or memorization of dialogues" (p.1). Traditional teaching methods used in the classes makes learners feel bored (Liu, 2010).

Autonomy is considered an important factor in learners' speaking ability. In order to make learners autonomous, 
Benson (as cited in Thanasoulas, 2002, p.9) suggests five types of practice ... follows resource-based (emphasis is on independent communication with materials); technology-based (emphasis is on education technologies); learner-based (learners' behaviors and psychological changes in them); classroom (relationship between learners and teachers) and curriculum-based approaches (extending learners' ideas, controlling, planning and evaluation to curriculum as a whole.)

It has been a controversial issue whether the teacher should be the authority of class or the facilitator. English teachers in conventional teaching are the authority of the class, in contrast to the recent decades which the teachers are facilitators in learners' skills and guides learners' learning through using computers and new technologies which seem essential; moreover, teachers are also good leaders for learners to use in class (Al- Issa \& Al- Quabtan, 2010).

\subsection{Teachers' Experiences in Adult and Young Students' Oral Activities}

Teachers can use new methods to encourage the ESL learners to take part in communication and speech with less stress. They should talk to learners and show that they understand them. They know it is not an easy responsibility, but it is necessary for them if they are going to learn a foreign language perfectly (Toste, 2011). To expand the learners' speaking ability and language skills, teachers can ask questions and learners should answer in a simple language in public speaking links and choice of words. Complexity of sentences is important when learners answer the question (Pan, 2010). According to Mayer (as cited in Liu, 2010, p.136) "when learners are motivated to learn, they try harder to understand thereby to learn more deeply, resulting in better ability to transfer what they have learned to new situations".

Oral reports or summaries which are extracted from newspapers or books, hotel brochures, and different menus could be used as an input in communicative interaction which give the learners the opportunity of real life they will confront in the future. Oral activities like dialogues and role-play would provide the chance to become confident in using target language.

\subsubsection{Different Ways to Improve Speaking}

Some visual devices can help learners as such as pictures, graphs and flash cards which can be used during learners' presentation (Pesce, 2013). Playing cards is considered as a proper tool for young learners in learning English (Kayi, 2006). Another way is implementing pictures which are examined during the grammar teaching to see its effects on learners' speaking and writing abilities in junior high school. The experimental groups learned the grammar that was taught implicitly through using pictures and making examples about the pictures by teacher. Then, learners are asked to individually or by classmates make sentence (orally) about pictures for homework. Learners' written sentences and posttest interviews were tape recorded and scored (Ghapanchi \& Sabouri, 2013).

Teachers can help learners to develop their speaking ability to communicate in foreign language, and at least the ability to use it in social interactions; age is an important factor to success or failure in 12 learning and speaking. there are three important factors in adult proficiency 12 learning; first of all maturational constrains in which fossilization -aging process may affect or fail adults' pronounce in fluently- they speak with good pronunciation but intonation, stress and the rest phonological problems still lead them to fail communication; adult learners don't have the same innate desire as kids for learning fluency in speaking foreign language.

Second, aural medium, which means listening has most important role in speaking improvement abilities, every speaker is a listener too. To responding a person the speaker should understand what is hearing with prior knowledge and information.

Third, sociocultural factors also affect 12 learning, using a language in context is different from one culture to another, so to speak foreign language, learner must know language's rulers and the use of it when, how and to what degree because the interference of learners' own cultural, also nonverbal message affects oral communication affective factors are emotions, empathy, self-esteem, attitude, anxiety and motivation that related to foreign language learning (Richard \& Renandya, 2002).

Speaking in public or in front of native person may causes anxiety, sometime tongue - tied or forgetting words in this situation cause discouragement and failure; adult learners' mistakes in some cultures show their inability in speaking.

Spoken language result in transactional and interactional in social relationship to convey ideas and new information, that means interaction is the key element to improving EFL students' speaking, so the classroom is a good place for communications in meaning focused activity, and students will learn to communicate in real life situations, small talk only same utterances at time, indeed they learn how to open and exchanges in conversations. The opportunity that learners have to speak language promote interaction, teacher must consider as willingness and need of students to speak, in order to stimulating them to talk (Richards \& Renandya, 2002).

Brouilltette (2012), In her study, states that texts are not effective ways to orally convey material for young learners, 
but utilizing drama or video lessons motivate oral language skills among teachers and learners. The learners who participate in a drama program were confident in their communications. For example, teacher gives the picture of an animal and students represents by using movement and sound to the class. Moreover, the teacher evaluates the comprehension of the learner at the same time. Much of speaking in EFL/ESL classes is done with preparation even if it is just a couple of minutes. In improvisation (a kind of activity done without preparation) learners' should make an act, react and move without preparing decisions about what they say or do; this is not necessary to know what comes next. Paying much attention to the communication forces them to listen and speak carefully and use language in an unplanned situation outside the class without preparing.

There is an observation oral activity of Oman's learners in some classes. Al-Issa et al. (2010) in their research on improving speaking in communications, point out that dynamic, reflective, independent learning and critical thinking are the features of oral presentation and learners are responsible for their own learning. This positive behavior in early decades is a good way to effect the future development. Teachers in EFL classrooms, in traditional way, are authority in controlling knowledge, information and the activities of class, but in oral presentation class teachers are facilitators to organize and guide learners learning. Using new technologies by learners are essential in this way and teachers are good leaders to use them. Different types of oral presentation are controlled, guided and free.

\subsubsection{Different Types of Oral Presentation (controlled, guided, and free)}

Learners' language proficiency in a controlled type is from beginner to elementary. Teacher gives topics or something with ease. The ages of learners in that language level are young (6-12) with no knowledge about computers, they should prepare their oral presentation on paper, or asking short questions and answers in pairs. The assessment in control groups is not available, since there are a few items of oral presentation. Learners are in lower intermediate level of language proficiency in guided type. Teachers guide learners to grammar and lexical item and learners must continue talking in a period of time without making language errors. Using Power Point or OHP (Overhead project is a variant of slide projector that is used to display images to an audience) are interesting, valid and professional materials at this level. It is possible that some learners memorize their presentations; however, seems dull, it may be helpful for memorizing phrases, lexical, expressions and structural items.

In the free type, learners are in upper-intermediate to advanced level usually 16-22 years old; they are free to choose the appropriate topic. They are capable to use complex language in longer presentation times followed by raising sophisticated questions rather than questions about the topic. Arranging learners in oral presentations class can be individually, paired or in groups of three or more learners depending on the size of the class, topic, and teacher's object. Internet, various books and texts, newspapers, pictures, and personal experience are relevant sources to obtain information and data for presentation topics. Researchers indicate that Arab learners of English have difficulties for making question in English. To solve this problem teacher may write the key words of the presentation topic and the necessary points for asking questions. Teachers give some questions on some papers to learners for asking the presenter. Therefore, the learners' reading, classroom participation, and confidence will be improved. The presenter should use body language and have eye contact to all classmates; thus, showing the class that he is confident enough in presentation. Teachers should present positive motivation (interest) in product (learners' fluency and accuracy) and process to have a holistic look in giving a fair assessment (Al- Issa \& Al- Quabtan, 2010).

According to Kayi (2006):

working in group is an effective way to increase learner's confidence. In some activities students are supposed to be working in pairs. One student will have the information that the other partner does not have and the partners will share their information. Information gap activity serves many purposes such as solving a problem or collecting information. Also, each partner plays an important role because the task cannot be completed if the partners do not provide the information the others need. These activities are effective since everybody has the opportunity to talk extensively in the target language (p.5).

One of the activities making them work in group is brainstorming. Teacher gives a topic to be discussed in a limited time. Learners produce ideas which deal with the context individually or in groups according to their mind. In this case, the learners are enabled to share new ideas without being criticized (Kayi, 2006). Another brilliant way in learning a new language is story telling. A heard story or tale can be summarized by learners; and also, they can create stories, reciting them to the classmates. It causes creative thinking and helps to express ideas and develop their mental abilities. Telling riddles and jokes affects thinking skill. Teachers call some learners to tell jokes and riddles to make others speak and continue the subject to foster their consideration and speaking ability (Kayi, 2006).

Interview is a useful group work which helps ESL learners to become more confident and be able to communicate 
with others. They would select a topic and interview with various people. Teachers can help learners by providing rubrics so that they become familiar with the type of questions to ask and give direction to follow, but preparing interview questions should be done by the learners. This type of communication gives chance to learners to speaking outside the class being more socialized. They should present their studies to the class (Kayi, 2006).

Another helpful aspect which is enjoyable for learners is story completion. It is a whole-class activity which learners have free-speaking as they sit in a circle. The teacher tells a story and after a few sentences stops narrating. Each student narrates the rest of the story by adding some sentences. They can change characters, descriptions, events and other elements they will (Kayi, 2006). Adult motivation in learning a new language is different from young students. Some of them lose their willingness to learn very quickly. Being tired after a course, lack of time and too many works and house hold duties are possible reasons of losing inclination. Some adults learn a language because it is necessary for their jobs and travels (Staib, 2008).

Some adults also have general occupational reasons to know an international language like communicate foreign clients. Moreover in some cases executives and the staff members are not native or local people. Therefore, they should have one common language in order to make relationship and work together. This motivates them to participate into EFL/ESL classes in spite of their willing (Cook, 2001).

In adult classes the number of women learners is more than men. It reveals that women are much motivated than men to take part in language learning classes in order to improve their speaking skill (Pattanapichet \& Chinaokul, 2011). Thus, English might be their handy tool for basic communication. At the very first meeting, teachers should find out motivation reasons for learning and make them realize the teacher will do the best to emphasis all the elements they are going to learn.

The other adult problem is that they understand quite complex texts, but when the teacher asks them to speak they feel embarrassed and avoid uttering even simple sentences. Teacher speaks to them about communication in speaking second language, Speaking is in real world, practice speaking in group is a good way to improve fluency makes student feel that they are learning being motivated to make more effort. Recording learners speaking is very useful tool showing their improvement in speaking. So they would be more eager to speak using authentic materials. Providing learners the ability to understand a real text written by a real English writer works as a success leading into great motivation. Asking learners to tell anecdotes is also a very good example giving learners a chance to speak English for longer time; making some questions connected with the speech activates other learners to summarizing the anecdote. They will achieve a large amount of vocabulary helping them to feel more confident (Staib, 2008).

\section{Pedagogical Implications}

It is difficult for EFL learners, especially adults, to speak the target language fluently and appropriately. In order to provide effective guidance in developing competent speakers of English, it is necessary to examine the factors affecting adult learners' oral communication, components underlying speaking proficiency, and specific skills or strategies used in communication. This paper explores these aspects to that teachers can more effectively help adult learners develop their abilities to communicate in the target language.

Teaching speaking a foreign language is urgent and teachers' role in this aspect is considerable, as they should encourage their students to be successful in every step of life, and also provide an environment of meaningful but not merely memorizing communication. Students should try to develop their basic interactive skills. There are different methods teacher can apply to motivate learners to study English especially adults who hesitate to take part in communications. One of the problems which causes failure in learning foreign language; while they need it. Oral tests, encouraging learners to interview, story- telling, working in groups, and other activities are pointed out throughout the article demonstrating speaking skill as a strong tool in communication.

\section{Conclusion}

In this research, a number of theoretical and functional aspects about oral presentation in foreign language learning classes were mentioned which are practical not only in EFL classes but also in purposed and English second language classes. Teachers can apply this article in other language learning classes, too. Most of the teachers stick to language materials and try to create benefit areas in their classroom for learning, but they will fail for motivating students, so language teaching should have difficult factors that promote success (Thanasoulas, 2002).

The ideas suggested in this article would be the cause of creativity, reflection, and innovation. Expert teachers attempt to manipulate there classes to be more exciting and attractive. People need to be complex, fluent and accurate 
in speaking $l_{2}$, because they are going to use it in selling and buying, passing an exam, doing international jobs , listening to music, traveling, writing a novel and many other activities (Cook, 2001).As most techniques considered, language learner should not to give up. It is not an easy task, but is possible. They should try to be more confident in order to achieve the goal which is speaking fluently with confidence.

\section{References}

Al-Issa, A., \& Al-Qubtan, R. (2010).Taking the floor: Oral presentations in EFL classrooms. TESOL Journal, 1(2).

Brouillette, L. (2012). Advancing the speaking and listening skills of English language learners in the primary grads through creative drama. TESOL, 3(1), 138-145.

Chastain, K. (1988). Developing second-language skills: Theory and practice.(3rd ed.). HBJ: San Diego New York Chicago Austin Washington,D.C.

Cook, V. (2001). Second language learning and language teaching. (3rd ed.).Oxford: Oxford University Press.

Cutron, P. (2009). Overcoming Japanese EFL learners' fear of speaking language. Language Studies Working Papers, (1), 55-63.

Ghapanchi, Z., \&Sabori, F. (2013). The implicit instruction of grammar via picture: A technique to improve writing and speaking abilities of Iranian elementary EFL learners. Iranian EFL Journal, 2(9), 208-221.

Kayi, H. (2006). Teaching speaking: Activities to promote speaking in a second language. TESOL, 11(12), 1-6. Retrieved from http://unr.edu/homepage/hayriyek

Lio, X. (2010). Arousing the college motivation in speaking English through role-play. International Education Studies, 1(3), 136-137.

Martin, D. (2003). How to get your students to speak 100\% English. EFL, 1-7 Retrieved March 2014 from http://www.eflpress.com/teachers/100html

Pan, L. (2010). A study on public speaking in Korean education for Chinese students. JLTR, 6(1), 922-925.

Pattanapichet, F., \& Chinaokul, S. (2011). Competencies needs in oral communication in English among Thai undergraduate public relations students: A substantial gap between expectation and reality. RELC,42(2), 187-202.

Pesce, C. (2013). Try these 7 sure-fire ways to boost student confidence. Retrieved May 2014 from http://www.lessonpath.com/learn./ideas/for-teaching/

Richards, J. C., \& Renandya, W. A. (Eds.). (2002). Methodology in language teaching: An anthology of current practice. Cambridge: Cambridge university press.

Skeffington, C.S. (2011). Getting teenagers talking. Retrieved May 2014 from http://www.teachingenglish.org.uk

Staib, K. (2008). 10 secrets to motivating teenagers. Retrieved May 2014 from http://www.workhappynow.com

Thanassoulas, D. (2002). Motivation and motivating in the foreign language classroom. The Internet TESOL Journal.11(8), 2-7.

Toste, V. (2011). Four ways to help hesitant student to speak in the classroom. English Language Teaching Global Blog. Retrieved May 2014 from http://outeltglobalblog.com.

Tutaj, K. (2011). Motivating adult learners. English language teaching the teacher. Retrieved May 2014 from http://www.teacher.pl/strefa/ 